\title{
Computer assisted management of warfarin treatment
}

\author{
R WILSON, A H JAMES
}

\begin{abstract}
Maintenance of anticoagulation is laborious and costly, and the results are often indifferent. An automatic system which adjusts the dose of warfarin has been designed using a formula devised after a survey of prescribing habits. Programs running on a microcomputer maintain a file of the necessary information and deal with the bulk of the weekly clinic. Dosage is advised, the date of the next visit determined, and the file updated. A doctor uses the console to advise some $10 \%$ of patients reserved for special reasons. The system produces clinic and ambulance lists, copies of the advice sent to patients, and, as a protection against machine failure, a weekly copy of the updated file.

The results after 16 months are at least as good as those achieved manually. Medical and secretarial time is saved, and statistics about the clinic and its efficacy are made available.
\end{abstract}

\section{Introduction}

Our anticoagulant clinic maintains about 260 patients taking warfarin, as well as a very few taking other drugs, which are here disregarded. About a fifth of the patients attend a weekly clinic; blood samples are taken and, after the patients have left, the British corrected ratio is determined in a batch and advice sent by post. The British corrected ratio is measured by the one stage prothrombin test on venous blood using Manchester comparative reagent (Quick test). Arrangements elsewhere may be different, but, however it is done, the procedure is laborious and expensive, and often relies on doctors in junior grades. Perhaps not surprisingly control is not good: it has been estimated that only a half of such patients are effectively anticoagulated. ${ }^{1}$ Apprehension has also been expressed about the adequacy of records, particularly whether the date when it is intended that treatment should stop may pass unnoticed, so that anticoagulation continues by default. ${ }^{2}$

We have devised an automated system to deal with the adjustment of warfarin dosage; Wiegman and Vossepoel have described a similar one as part of a hospital information system running on a mainframe computer. ${ }^{3}$ Their system is similar to ours in that it provides a recommended dose in terms of the previous dose and the current coagulation time and recommends \footnotetext{
Department of Medicine, Hillingdon Hospital, Uxbridge, Middlesex
UB8 3NN

$\mathrm{R}$ WILSON, MB, MRCP, medical registrar

A H JAMES, DM, FRCP, consultant physician

Correspondence to: Dr A H James.
}

the interval before the next visit. We are, however, unaware of the use of a microcomputer for this purpose, or of the adaptation of the program to the circumstances of a district general hospital.

\section{Methods}

Survey-A questionnaire was given to members of the junior medical staff at Hillingdon concerning their practice in prescribing warfarin dosage and intervals between tests. Hypothetical situations were posed in which patients taking warfarin in various doses had various British corrected ratios. Opinions were asked whether temporary cessation of treatment was needed, and if so for how many days: what dose should be advised; and when the next test should be done. A similar questionnaire was sent to the consultants in charge of anticoagulant treatment at some neighbouring hospitals, and six responded. From the answers obtained, criteria for answering these three questions could be defined, and formed the central logic of a computer program.

\section{Computer system}

Programs were written for a Commodore PET 4032 microcomputer. These maintain a file of necessary information, with space for 350 patients. The largest program deals with the clinic results and advises: (a) a modified dose, suitably rounded (small changes are cancelled); (b) whether treatment should be temporarily interrupted; and $(c)$ when the next visit should be. It automatically updates the file. Cases where discontinuance is due, or showing overanticoagulation (British corrected ratio $>5$ ), non-attendance, or non-compliance are reserved for a doctor. He uses the console to see the information and give his advice. The remainder of the program is devoted to administrative and statistical requirements.

If circumstances arise which require that the computer's advice should be overridden, this can easily be done, and the file amended with the program designed for this purpose. Most often it is the date of the next visit which has to be changed for one reason or another.

Another program prints an alphabetical list of patients due at the next clinic, marking those with a current British corrected ratio less than $1 \cdot 8$, so that their treatment can be discussed with them. Documentation includes a user manual and technical reference notes. A weekly printout of the entire file guards against machine failure.

\section{Results}

Figure 1 shows the ratio of the new recommended dose of warfarin to the former dose for each observer and each British corrected ratio (BCR) in the survey of Hillingdon junior doctors. In fig 2 the mean ratio for all observers is plotted against $\log _{e} B C R$ : the relationship is nearly linear, and is described by the equation $\mathrm{M}=1+0 \cdot 58 \log _{\mathrm{e}}(2 \cdot 6 / \mathrm{BCR})$

where $M$ is the ratio of doses. The figure 2.6 represents the British corrected ratio at which $M$ is equal to unity-that is, the British corrected ratio at which the dose adjustments are apparently aimed.

The answers from other hospitals gave similar results except that the dose tended to be reduced rather less for high British corrected 
ratios. We use the formula as above, except that the figure of 2.6 is replaced by a variable, $T$, which is filed as the "target British corrected ratio" for each patient, and which can be altered to suit his case.

Answers concerning interruption of treatment indicated that all would do this for two or three days when the British corrected ratio was 5 or more; some would interrupt treatment for one day when the British corrected ratio was 4. Our program recommends one day of interruption if the British corrected ratio is $4 \cdot 4-4 \cdot 6$, two days

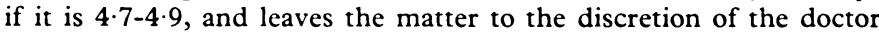
for higher levels.

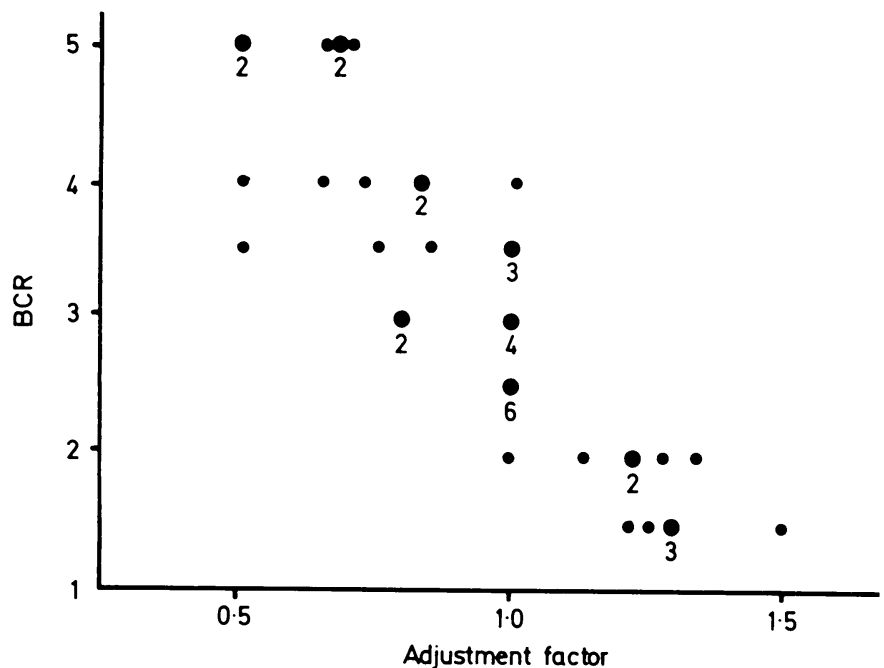

FIG 1-Prescribing habit survey: adjustment factor recommended by each of six prescribers (mean for all doses) plotted against British corrected ratio. The figures below the larger dots indicate the number of coincident values.

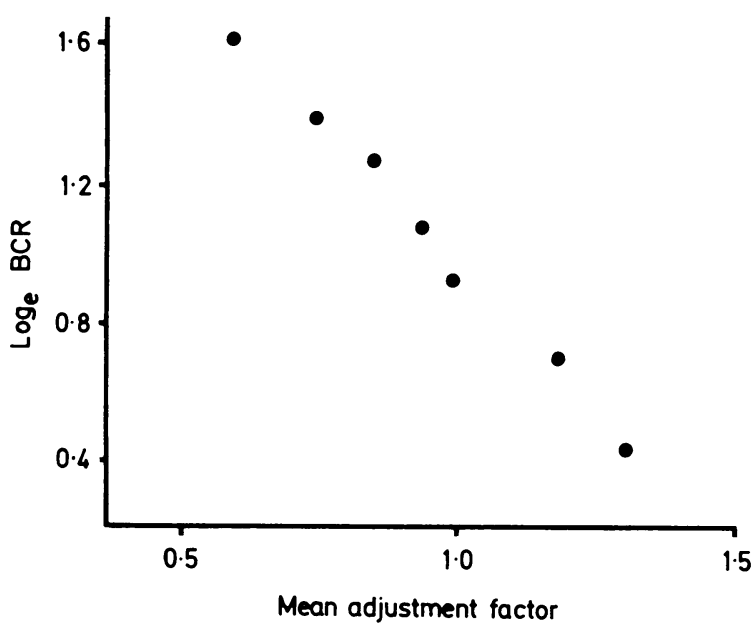

FIG 2-Prescribing habit survey: mean adjustment factor for all observers and all doses is plotted against British corrected ratio. The relationship is approximately linear, and when the adjustment factor is unity the equivalent value of the British corrected ratio is $2 \cdot 61$.

Future visits were more difficult to formulate. Some doctors allowed a three month interval between visits; others not more than four weeks. We have followed our traditional practice of making six weeks the maximum interval. If the patient does not attend or the blood sample clots a one week interval is obligatory, and patients who have recently started taking warfarin are seen every one or two weeks according to their British corrected ratio. Provided the British corrected ratio is not greater than $3 \cdot 7$, a maximum interval of six weeks is allowed if the dosage has shown a certain degree of stability: the absolute value of $1-D_{1} / D_{2}$, where $D_{1}$ and $D_{2}$ are the values of successive doses, is calculated for each of the last four pairs of doses. If the sum of these four values does not exceed $0 \cdot 464$, then the dosage is judged to be sufficiently stable to permit the maximum interval.

If these various criteria are not met, the interval is based on the previous interval and the factor by which the dose has just had to be altered. The general principle is to allow a gradual increase of the interval to a maximum of six weeks provided that dose adjustments are small. In the cases referred to the doctor, the interval to the next visit is at his sole discretion.

Running of programs-The programs have proved effective in practice. Although the initial entering of the cases was laborious it was achieved without extra staff. The clinic has run fairly smoothly after the first three weeks; since then difficulties have twice required a rerun, but it has never been necessary to return to a manual system. Entering and checking the data take about 15 minutes, and the automatic calculating, labelling, and file amendment 15-20 minutes according to the number of patients. There have been no hardware failures in 16 months.

Effect on working-Patients were informed of the intended change and shown sample labels. Very rare misinterpretations of the labels have occurred, mainly owing to the lack of a character representing $1 / 2$. Patients' comments have been favourable. There has been a large saving of the house physician's time: dealing with the whole clinic manually used to take about two hours, but under this system it takes only a few minutes. We have recently abandoned manual files, saving secretarial time as well as some filing space. In the event of a machine failure the updated file is available as hard copy, and the clinic could be run manually with its aid. We estimate that the net saving of secretarial time is half a day per week.

Effect on performance-Our first comparison of management by hand and by computer during a three month period gave the results shown in the table. As it seemed likely that the computer system

Comparison of 132 patients managed manually in August-September 1982 and by computer in August-September 1983

\begin{tabular}{lccc}
\hline & $\begin{array}{c}\text { Average British } \\
\text { corrected ratio }\end{array}$ & $\begin{array}{c}\text { Average interval } \\
\text { between visits } \\
\text { (weeks) }\end{array}$ & $\begin{array}{c}\text { "Outside British } \\
\text { corrected ratio } \\
2-4\end{array}$ \\
\hline 1982 (manual) & 2.52 & 4.84 & $17 \cdot 4$ \\
1983 (computer) & $2 \cdot 79$ & 3.91 & $14 \cdot 2$
\end{tabular}

These patients had all been treated for at least three months before the first period surveyed.

was requiring patients to attend rather more often than formerly, the program was modified, with a subsequent lengthening of the average interval from 4.6 weeks to 5.2 weeks. During the last six weeks the proportion of patients with British corrected ratios over $\mathbf{4}$ has averaged $1.5^{\circ}{ }_{0}$ and with British corrected ratios under $2,18^{\circ}{ }_{0}$.

\section{Discussion}

Computer assisted warfarin treatment seems to be at least as good as treatment managed by hand: the proportion of patients whose British corrected ratio lies between the recommended limits of 2 and $4\left(80-85^{\circ} \%\right)$ compares favourably with such estimates as there are from conventionally run clinics. ${ }^{4}$ The weekly printout showing these proportions and the average level attained serves as an internal audit.

We also find it very advantageous to be reminded automatically that discontinuance of treatment is due. When there are less than seven weeks of treatment to go a message is displayed asking for a "warning letter" to be sent to the referring consultant, who is thus able to confirm or otherwise his intention to stop treatment. With less than four weeks to go the case is displayed to the doctor for discontinuance. We therefore feel confident that no patient's treatment is prolonged through oversight or shortened contrary to current intention.

Overall control of treatment-The computer system makes it possible not only to monitor performance over the whole group of patients but also to alter the criteria for treatment by changing the "target British corrected ratio," either for the whole group or for individual patients.

Drugs-We do not record concomitant drug treatment. If drugs which affect warfarin treatment are being given throughout an interval between one visit and the next, we 
should still adjust the dosage in terms of the current British corrected ratio. If such drugs are started or stopped during the interval, they might indeed affect the prothrombin level, and ad hoc arrangements might have to be made, as they easily can be, to readjust the dosage and the date of the next visit, and to amend the file. We think that the best way to avoid unfavourable drug interaction is to remind patients and their general practitioners of its possibility from time to time.

Conversion for use elsewhere-Should others wish to use this system it would require slight modification. Adaptation to Thrombotest would present no difficulty. For the programs to be available to a wider range of microcomputers it would be necessary for them to be rewritten to run under one of the standard disc operating systems, and adjustment to different printers would require attention. We think that this system would be helpful to many hospitals and improve the standard of anticoagulant maintenance.

We thank Mr D R John and Mr J Cox for allowing us to use the microcomputer belonging to their department.

\section{References}

1 Duxbury $\mathrm{BMcD}$. Therapeutic control of anticoagulant treatment. $\mathrm{Br}$ Med $\mathfrak{f}$ $1982 ; 284: 702-4$.

Shafi M, Mayberry J, Calcraft B. An audit of a medical anticoagulant clinic in a district general hospital. Postgrad Med $\mathcal{F}$ 1983:59:492-4. control. Computer Programs in Biomedicine $1977 \cdot 7: 71-84$. Vorm anticoagulation

4 McInnes GT. Efficacy of anticoagulation in the UK. Lancet $1981 ; \mathrm{ii}: 88$.

(Accepted 15 fune 1984)

\title{
Lesson of the Week
}

\section{"I have a bone stuck in my throat"}

\author{
N KIRKHAM， RUTH ENGLISH
}

When a foreign body such as a fish bone or a chicken bone is accidentally swallowed it may stick in the hypopharynx or cervical oesophagus. Food bones are often poorly calcified and may be very difficult to see on lateral radiographs of the neck. We describe two patients who died of septic complications when bones lodged in their throats and were not removed.

\section{Case reports}

Case 1-A 65 year old woman swallowed a fish bone, which lodged in her throat. She attended the accident and emergency department on the next day, where a lateral radiograph of the neck failed to show a foreign body. The patient's history of psychiatric illness was noted and she was sent home without any further examination. She returned three days later when the bone was found lodged transversely across the hypopharynx. It was removed but shortly afterwards she developed a cardiac arrhythmia and collapsed. After an initial recovery she collapsed again and died five days after removal of the bone. At necropsy the principal findings were oedema of the hypopharynx and cervical oesophagus, perforation of the oesophagus, and suppuration in the surrounding tissues.

Case 2-A 25 year old woman, who had suffered from cerebral palsy since birth, was brought to the accident and emergency department. While being fed her liquidised meal from a spoon, a bone had been missed. This had then lodged in her throat, causing considerable distress. The unfortunate combination of spasticity and distress made indirect laryngoscopy impossible without a general anaesthetic. This was thought to be inadvisable because of the danger of asphyxiation during induction. A lateral radiograph did not appear to show a foreign

Southampton General Hospital, Southampton SO9 4XY

N KIRKHAM, MB, MRCPATH, lecturer in pathology

RUTH ENGLISH, $M B$, MRCP, registrar in radiology Correspondence to: Dr Kirkham, Department of Histopathology, Royal
Sussex County Hospital, Brighton BN2 5BE.

\begin{abstract}
Any patient claiming to have swallowed a bone and to have it stuck in his throat should be believed. The bone will probably not show in a lateral radiograph of the neck. The bone must be looked for and removed: otherwise the patient may die of septic complications
\end{abstract}

body. Clinically the patient was thought not to have a foreign body in her throat. Two days later she died. At necropsy a piece of bone $3 \mathrm{~cm}$ long was found lodged in the left piriform fossa, with oedema and inflammation of the surrounding mucosa and an associated aspiration pneumonia. The bone was very poorly calcified and only weakly radio-opaque at the exposures routinely used for soft tissue radiography. Review of the original neck radiograph showed that the difficulties of positioning the cassette had resulted in a film which showed the neck only down to the second cervical vertebra. The top of the bone was just visible at the edge of the film.

\section{Discussion}

Food bones show a variable degree of radio-opacity. Chicken bones are hollow with a wide medullary cavity and thin cortex, mimicking the appearance of human phalanges. ${ }^{1}$ Bachmann has shown that fish bones show appreciable variation between different species. Trout and mackerel have poorly calcified bones, while salmon bones are more opaque. Cooking does not alter the degree of opacity. We have confirmed these findings in a small study in which we took $x$ ray films of uncooked and cooked fish and meat bones in situ in a cadaver and also in a tissue equivalent phantom neck. All but the smallest and thinnest of bones were visible.

The best results from radiological examination are obtained with carefully positioned and exposed films, when a high degree of diagnostic accuracy is possible. About $75 \%$ of bones should 